\title{
Research and application of coal and gas outburst early warning system based on gas geological features
}

\author{
Yunlong Zou ${ }^{1,2,3, *}$ \\ ${ }^{1}$ State Key Laboratory of the Gas Disaster Detecting, Preventing and Emergency Controlling, Chongqing, 400037, China \\ ${ }^{2}$ Chongqing Research Institute of China Coal Technology and Engineering Group Crop., Chongqing, 400037, China \\ ${ }^{3}$ School of Resources and Safety Engineering, Chongqing University, Chongqing, 400044, China
}

\begin{abstract}
The geological structure of coal mines has always been a dangerous object of attention in coal mine outburst prevention work. In order to realize coal mine safety information management and early warning of gas disasters, comprehensive use of gas geological theory, coal mine disaster warning theory, computer information technology and other analysis methods, considering the influence of geological structure, coal seam occurrence parameters, and gas parameters, an early warning indicator system for identifying the risk of coal and gas outbursts reflecting the geological characteristics of gas has been constructed. The coal and gas outburst risk identification and early warning system is constructed using the principle of multi-index step-by-step identification and extreme value determination, and it is applied on-site in the 3303 Measure Lane in the East Shaft Area of Sihe Mine. The research results show that the constructed early warning system can provide accurate early warning for the area (belt) affected by the geological structure by $10 \mathrm{~m}$, and can provide accurate early warning of coal and gas outbursts based on the outburst signs of gas geology such as the thickness of soft layers and changes in coal seam thickness. This technology provides effective support for coal mines to effectively prevent gas disasters and ensure coal mine production safety.
\end{abstract}

\section{Introduction}

Coal and gas outburst disasters occur frequently, causing mass deaths and injuries [1-2]. There are many factors influencing the risk of coal and gas outbursts, and there are many indicators that can directly or indirectly reflect one or more aspects of the outburst risk of coal seams [34]. The overall highlight of the hazardous environment, and the factor that can reflect the outstanding hazardous environment is the gas geological environment. The gas geological environment (geological structural environment and gas pressure and other occurrence parameters) objectively determines the overall severity of the outburst hazard of the working face, and belongs to the grasp of the macroscopic primitive environment of the coal seam. The theory of gas geological zoning believes that: geological structure has obvious control effect on the outburst risk of coal seam, and geological structure controls the distribution of outburst risk by controlling the occurrence of gas, coal body structure type and tectonic stress. The statistical results of the outbursts show that more than $80 \%$ of outbursts occur near faults and other geological structures [5-6].

From the analysis of outburst mechanism, geological structure has three effects on gas outburst: (1) due to the influence of geological activities, the coal seam structure near the geological structure is often destroyed, most of which are accompanied by structural soft coal. The coal body has low strength and resists outburst damage. (2) there are often high residual tectonic stresses near geological structures, and the distribution is uneven, which increases the kinetic energy of outbursts. (3) some geological structural environments will create a closed environment and cause high gas pressure in the coal body. Therefore, geological structure has always been a dangerous object of great concern for outburst prevention work [7-10]. The establishment of a gas geological early warning system suitable for the specific conditions of mines can realize the information management of mine safety and the early warning of mine gas disasters. It will be one of the important technical means for coal mines to effectively prevent gas disasters and ensure coal mine production safety in the future.

\section{Establishment of gas geological early warning indicator system}

The coal seam in the area where the 3303 Measure Lane in the east shaft area of Sihe Mine is located is about $6.6 \mathrm{~m}$ thick, the floor elevation is $610 \sim 630 \mathrm{~m}$, and the burial depth is about $440 \mathrm{~m}$. According to the gas geological map of the east zone, the original gas content of the coal seam in the area where the 3303 Measure Lane is located is about $14 \mathrm{~m}^{3} / \mathrm{t}$. After the formation of the 3303 working face, bedding boreholes were constructed along the lanes 33033 and 33032 from both sides of the trench, and gas was pre-drained. Therefore, the gas content of the coal in the 3303 working face has been greatly reduced.

\footnotetext{
*Corresponding author: 2010152@cqceteg.com
} 
Nevertheless, the gas gushing out during the 3303 working face was still large, and gas exceeding the limit occurred. It can be inferred that the gas content in this area is still high. In addition, the coal body in this area is affected by the thinning zone of the coal seam, and there is a large amount of soft coal. Therefore, the outburst risk of the coal seam in the area where the 3303 Measure Lane is located is relatively high.

The 3303 measure lane was excavated from 2010/9/25 to the end of 2010/10/30. The tunneling method was blasting, using bolt-net support. During the tunneling process, it was managed according to the outburst prevention face, and local comprehensive outburst prevention measures were taken. The 3303 measure lane is located at the 3303 working face of the Dongsanpan area. There is a coal thinning zone in front of the roadway. The purpose of this roadway is to provide a place for the construction of the 3303 working face to cross the coal thinning zone. According to the design, the 3303 Measure Alley is driven northward from Lane 33033 (54\# Hengchuankou location). It first excavates $10.5 \mathrm{~m}$ uphill at $16^{\circ}$, and then excavates $108 \mathrm{~m}$ horizontally along the roof of the coal seam, as shown in Figure 1.

The gas geological early warning index system is established by mainly considering the geological structure, coal seam occurrence parameters, and gas parameters [1112], as shown in Figure 2.

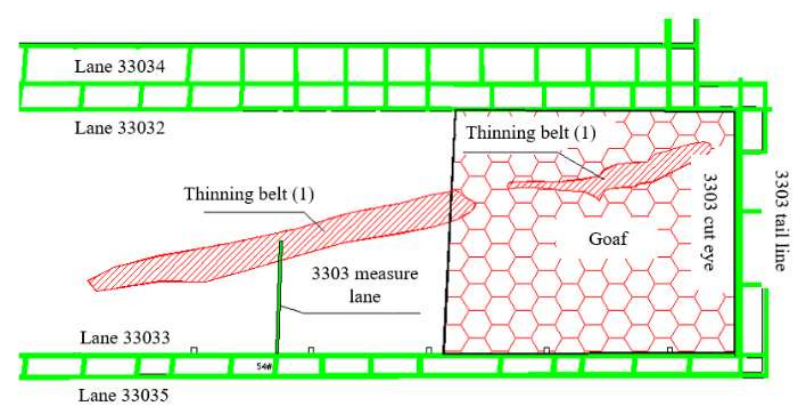

Figure 1. Layout of 3303 measure lane

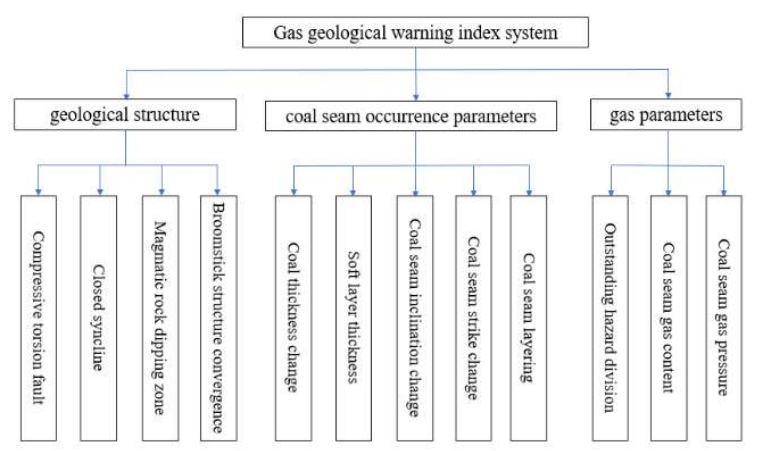

Figure 2. Gas geological early warning indicator system

\section{Construction of risk identification model for coal and gas outburst}

According to the implementation steps of highlight early warning, it is necessary to analyze, process and calculate the collected various hazard source information related to highlight to obtain various specific and quantitative highlight early warning indicators. On this basis, according to the police analysis model, the possibility, hazard and development trend of disasters are analyzed to determine the degree of disaster risk. Automated early warning needs to rely on computer technology to abstract the entire early warning realization process by computer, and also need to build a corresponding algorithm model. Therefore, according to the coal and gas outburst early warning process, the gas outburst early warning model based on the geological characteristics of gas mainly includes the following three parts:

(1) The comprehensive early warning model is used to analyze the warning situation and determine the warning level according to the warning indicators.

The development trend of outstanding danger is to judge whether the degree of outstanding danger on the working face tends to increase or decrease with the continuation of time or space according to the changes of monitoring indicators. For example, as the distance between the working face and the geological structure shrinks, the outburst hazard gradually becomes more serious, and as the working face enters the effective pressure relief area of the protective layer, the outburst hazard tends to be reduced or eliminated. Since the development trend generally belongs to the macroscopic identification, referring to the alertness expression methods in other fields, the alert level of the prominent trend is divided into three levels, which are represented by green, orange and red respectively. For this reason, the coal and gas outburst early warning system has been established, and its classification, grade and meaning are shown in Table 1.

Table.1 Coal and gas outburst early warning system and description

\begin{tabular}{|c|c|c|}
\hline Type & Grade & Explanation \\
\hline \multirow{4}{*}{$\begin{array}{c}\text { Status } \\
\text { warning }\end{array}$} & Normal & $\begin{array}{c}\text { Various indicators of the working face } \\
\text { are normal and safe operation is } \\
\text { possible. }\end{array}$ \\
\hline & Threat & $\begin{array}{l}\text { Prominent prediction of the working } \\
\text { face is not dangerous or needs to be } \\
\text { determined, but it needs to focus on and } \\
\text { strengthen management. }\end{array}$ \\
\hline & Danger & $\begin{array}{l}\text { The working face has protruding danger, } \\
\text { it is necessary to stop the operation and } \\
\text { take anti-outburst measures or further } \\
\text { confirm the protruding danger. }\end{array}$ \\
\hline & Catastrophe & $\begin{array}{c}\text { The working face has been prominent, } \\
\text { and emergency response measures } \\
\text { should be taken, power off and } \\
\text { evacuation. }\end{array}$ \\
\hline \multirow{3}{*}{$\begin{array}{c}\text { Trend } \\
\text { warning }\end{array}$} & Green & $\begin{array}{l}\text { The protruding danger ahead tends } \\
\text { towards safety. }\end{array}$ \\
\hline & Orange & $\begin{array}{c}\text { There may be danger at a certain } \\
\text { distance ahead, please call attention. }\end{array}$ \\
\hline & Red & $\begin{array}{l}\text { The prominent danger ahead tends to be } \\
\text { serious, and we should focus on, } \\
\text { strengthen management, and strengthen } \\
\text { measures. }\end{array}$ \\
\hline
\end{tabular}


(2) The preprocessing model is used for the acquisition, prediction and calculation of various early warning indicators.

Early warning indicators are the basis for monitoring and early warning. In the established coal and gas outburst comprehensive early warning indicator system, some indicators can be directly obtained and used to determine the outburst hazard level, such as the amount of drill dust $S$ in the daily forecast index, and the drilling cuttings gas desorption index $K_{1}, \Delta h_{2}$, etc. Some indicators need to establish a certain prediction model to obtain through calculations, such as gas pressure or gas content, and the scope of the division of prominent dangerous areas. Some indicators need to be calculated professionally, such as the range of influence of geological structure, the rate of change of coal seam thickness, and gas emission dynamic indicators. Some indicators belong to the qualitative category and need to be quantitatively processed through a certain model before they can be used, such as blowholes, top drills, etc., outburst coal seam damage types, and blank areas of outburst prevention measures. Therefore, building a series of specialized analysis models and pre-calculating and processing early warning indicators can achieve indicator acquisition and early warning.

(3) Method realization model, used for the realization of related algorithms of computer graphics processing.

The early warning system needs to dynamically monitor various hazards in the production process, and needs to quickly transmit and calculate a large amount of monitored data. It must rely on computer technology to realize it, especially the computer realization of some preprocessing models. Drawing and correction of gas pressure contours, delimitation of outlier dangerous areas, automatic identification of stress superimposition, automatic calculation of space distance, automatic correction of floor contours, drawing of coal seam depth based on floor contours and topographic maps value lines, etc., not only need to be calculated but also need to be visualized, but also need to involve the generation of isoline models and isoline conversion space surface models using the grid method in computer graphics processing.

\section{Analysis of the application effect of the early warning model}

\subsection{Geological structure influence area (belt)}

During the excavation of the 3303 Measure Lane, a total of 50 early warnings were carried out for the geological structure-influenced area (belt), and the early warning conditions are shown in Table 2. After investigation and analysis, the above-mentioned early warning results are all correct. The boundary of coal seam erosion zone in 3303 Measure Lane is located $81 \mathrm{~m}$ away from the opening. In the process of roadway excavation, the change of soft coal layer thickness and daily prediction index with the roadway length is shown in Figure 3. It can be seen from the figure that within $40 \mathrm{~m}$ from the coal seam erosion zone, the thickness of the soft layer and the daily predictive indicators are significantly different from other areas. In this area, soft coal stratification is common and thick (all larger than $0.5 \mathrm{~m}$, and the thickest part of the roadway is all soft coal). At the same time, the daily forecast index is too large, and some circulation forecast indexes exceed the standard (the maximum $\mathrm{K} 1$ is 0.62 $\mathrm{mL} / \mathrm{g} \cdot \mathrm{min}^{1 / 2}$, and the maximum $\mathrm{S}$ is $8.4 \mathrm{~kg} / \mathrm{m}$ ). The above analysis fully shows: near the coal seam erosion zone, the outburst risk of coal seams is greater; and the influence range of the coal seam erosion zone in the Sihe mining area is determined to be $30 \mathrm{~m}$, and the outer $10 \mathrm{~m}$ is used as a buffer area, and early warning control is very scientific, reasonable.

Table.2 Special warning statistics of gas geological and geological structure affected area (belt) in 3303 Measure Lane

\begin{tabular}{|c|c|c|}
\hline Warning type & $\begin{array}{c}\text { Warning } \\
\text { result }\end{array}$ & $\begin{array}{c}\text { Total number of } \\
\text { times }\end{array}$ \\
\hline \multirow{4}{*}{$\begin{array}{c}\text { Status } \\
\text { warning }\end{array}$} & Normal & 27 \\
\cline { 2 - 3 } & Threat & 23 \\
\cline { 2 - 3 } & Danger & 0 \\
\cline { 2 - 3 } & Total & 50 \\
\hline \multirow{3}{*}{$\begin{array}{c}\text { Trend } \\
\text { warning }\end{array}$} & Green & 26 \\
\cline { 2 - 3 } & Orange & 5 \\
\cline { 2 - 3 } & Red & 29 \\
\cline { 2 - 3 } & Total & 50 \\
\hline
\end{tabular}

The 3303 Measure Lane reached a position $42 \mathrm{~m}$ away from the opening after $2 \mathrm{~m}$ of excavation on $2010 / 10 / 18 / 6$. At this time, the working face is $39 \mathrm{~m}$ away from the boundary of the coal erosion zone and has entered within $10 \mathrm{~m}$ of the periphery of the erosion zone. The trend warning result of the corresponding warning system gas geology special warning is "orange". Afterwards, the working face continued to excavate and reached a position $52 \mathrm{~m}$ away from the opening after $2 \mathrm{~m}$ of excavation on the shift working face on 2010/10/20/6. The working face was $29 \mathrm{~m}$ away from the boundary of the coal scour zone and entered the affected area of the scour zone. Correspondingly, the state warning result of the special warning of gas geology is upgraded to "threat", and the trend warning result is upgraded to "red". From then on to the shift of 2010/10/28/6, the 3303 measure road was dug in place ( $83 \mathrm{~m}$ from the opening), and the working face has been within the erosion range of the coal seam thinning zone. The corresponding state warning result of the special warning result of gas geology is "threatening", and the trend warning result is "red". 


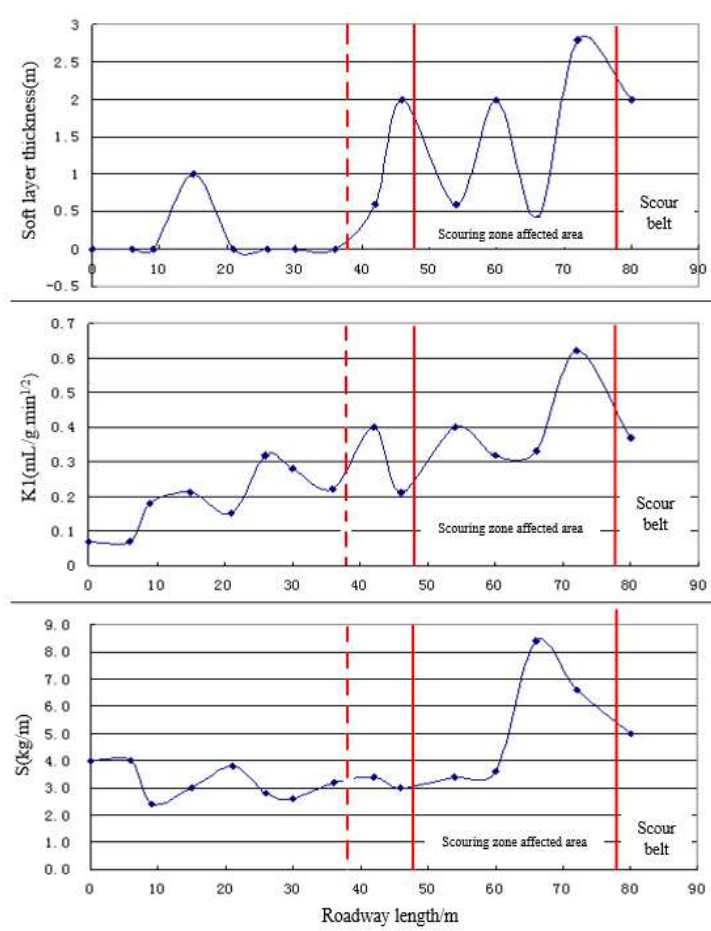

Figure 3. The daily forecast index and soft layer thickness of 3303 Measure Lane change with the length of the roadway

\subsection{Prominent signs}

Table 3 shows the statistics of the special warning results of gas geology under the condition of abnormal coal seam structure, coal seam occurrence, and soft layer thickness during the follow-up investigation. It can be seen from the table that the outburst signs of gas geology in Sihe Mine are mainly soft layer thickness and coal seam thickness changes. During the trial operation of the early warning system, when there are outliers such as abnormal soft layer thickness or drastic changes in coal seam thickness on the working face, the special warning of gas geology of the early warning system accurately gives the status warning results of the "threat" level. It can give early warnings to coal and gas outbursts based on the outburst signs of gas geology such as soft layer thickness and coal seam thickness changes.

Table.3 Special early warning statistics of gas geological signs and abnormalities in the follow-up investigation of the working face

\begin{tabular}{|c|c|c|c|c|}
\hline No. & $\begin{array}{l}\text { Working } \\
\text { face name }\end{array}$ & Shift & $\begin{array}{l}\text { Prominent } \\
\text { signs }\end{array}$ & $\begin{array}{c}\text { Warning } \\
\text { result }\end{array}$ \\
\hline 1 & \multirow{6}{*}{$\begin{array}{c}3303 \\
\text { Measure } \\
\text { Lane }\end{array}$} & 2010/10/6/6 o'clock & $1 \mathrm{~m}$ soft coal & Threat \\
\hline 2 & & $\begin{array}{c}\text { 2010/10/18/18 } \\
\text { o'clock }\end{array}$ & $0.6 \mathrm{~m}$ soft coal & Threat \\
\hline 3 & & 2010/10/21/6 o'clock & $0.6 \mathrm{~m}$ soft coal & Threat \\
\hline 4 & & 2010/10/23/0 o'clock & $0.4 \mathrm{~m}$ soft coal & Threat \\
\hline 5 & & $\begin{array}{c}\begin{array}{c}2010 / 10 / 24 / 12 \\
\text { o'clock }\end{array} \\
\end{array}$ & $2.8 \mathrm{~m}$ soft coal & Threat \\
\hline 6 & & 2010/10/28/0 o'clock & $\begin{array}{l}\text { The thickness } \\
\text { of the coal } \\
\text { seam changes } \\
\text { drastically }\end{array}$ & Threat \\
\hline
\end{tabular}

\section{Conclusion}

(1) Research and establish an early warning indicator system based on gas geological characteristics and three types of models required for early warning realization based on the model of highlighting the cause of the accident and the basic theory of highlighting prevention technology.

(2) The constructed gas geology special early warning system can provide accurate warnings of $10 \mathrm{~m}$ ahead of the geological structure influence area (belt) of the 3303 Measure Alley, and at the same time, it can monitor the coal and gas outbursts according to the gas geological outbursts such as the thickness of soft layers and changes in coal seam thickness. The gas outburst made early warning reminders, which provided decision-making support for the coal mine on-site outburst prevention work.

\section{Acknowledgments}

The study was supported by the Special Fund Project for Safety Production in Chongqing (Coal Development) (2020B182 [5985] 20015501), Chongqing Research Institute Independence Project (202001120).

\section{References}

1. Zhang Chaolin, Wang Enyuan, Wang Yibo, et al. The temporal and spatial distribution of coal and gas outburst accidents in my country in the past 20 years and suggestions for prevention and control[J]. Coal Geology and Prospecting, 2021, 49(04): 134-141.

2. Tan Guowen. Highlight the construction of a diversified precision prevention and control system for mine gas disasters[J]. Mining Safety and Environmental Protection, 2020, 47(03): 49-53.

3. Zhang Qinghua, Lin Huiqin, Wang Qixiang, et al. Exploratory analysis of gas occurrence and distribution based on gas geological information platform[J]. Mining Safety and Environmental Protection, 2014, 41(05): 101-104.

4. Wei Zhonghua. Research on the influence of geological structure on the risk of coal and gas outburst[J]. Energy Technology and Management, 2020, 45(02): 31-32+78.

5. Li Junhu. Safety analysis of roadway driving through fault under deep mining conditions in coal mines[J]. Energy and Conservation, 2021(02): 43-45.

6. Lin Xiaobo, Guo Liquan. Comprehensive analysis and evaluation of the safety risk of tunneling through faults in deep mining of coal mines[J]. Coal Mine Safety, 2020, 51(03): 200-206.

7. Yao Yahu. Application of multi-parameter outburst warning technology based on gas geological characteristics in new coal mines[J]. Mining Safety and Environmental Protection, 2021, 48(03): 94-99.

8. Wen Hengcong, Li Xuechen, Liu Baobao, et al. Advanced detection system for geological structure 
in high gas mining area[J]. Coal Mine Safety, 2021, 52(03): 165-169.

9. Qin Muguang. Application of gas geological dynamic analysis technology system in Yanghe Coal Industry $[\mathrm{J}]$. Energy and Environmental Protection, 2020, 42(06): 69-72+76.

10. Pan Xin, Yu Baozhong. Research and application of multi-stage dynamic gas geological analysis system [J]. Energy and Environmental Protection, 2020, 42(04): 56-60.

11. Qin Muguang, Zhao Xusheng, Zhang Qinghua, et al. Research on outburst warning model based on gas geological characteristics[J]. Coal Science and Technology, 2018, 46(12): 138-144.

12. Zheng Lei, Jiang Qian. Research on the role of gas geology in the establishment of outburst warning index system[J]. Zhongzhou Coal, 2016(08): 65$68+109$. 